\title{
SCIENTIFIC REP RTS OPEN Carbon dioxide induced plasticity of
branchial acid-base pathways in an
estuarine teleost
}

Received: 09 December 2016

Accepted: 02 March 2017

Published: 05 April 2017

\section{Elizabeth B. Allmon \& Andrew J. Esbaugh}

Anthropogenic $\mathrm{CO}_{2}$ is expected to drive ocean $\mathrm{pCO}_{2}$ above $1,000 \mu$ atm by 2100 - inducing respiratory acidosis in fish that must be corrected through branchial ion transport. This study examined the time course and plasticity of branchial metabolic compensation in response to varying levels of $\mathrm{CO}_{2}$ in an estuarine fish, the red drum, which regularly encounters elevated $\mathrm{CO}_{2}$ and may therefore have intrinsic resilience. Under control conditions fish exhibited net base excretion; however, $\mathrm{CO}_{2}$ exposure resulted in a dose dependent increase in acid excretion during the initial $2 \mathrm{~h}$. This returned to baseline levels during the second $2 \mathrm{~h}$ interval for exposures up to 5,000 $\mu \mathrm{atm}$, but remained elevated for exposures above $15,000 \mu \mathrm{atm}$. Plasticity was assessed via gene expression in three $\mathrm{CO}_{2}$ treatments: environmentally realistic 1,000 and $6,000 \mu$ atm exposures, and a proof-of-principle $30,000 \mu \mathrm{atm}$ exposure. Few differences were observed at 1,000 or $6,000 \mu \mathrm{atm}$; however, $30,000 \mu \mathrm{atm}$ stimulated widespread up-regulation. Translocation of V-type ATPase after $1 \mathrm{~h}$ of exposure to $30,000 \mu \mathrm{atm}$ was also assessed; however, no evidence of translocation was found. These results indicate that red drum can quickly compensate to environmentally relevant acid-base disturbances using baseline cellular machinery, yet are capable of plasticity in response to extreme acid-base challenges.

Anthropogenic $\mathrm{CO}_{2}$ emissions have been rising rapidly since the industrial revolution causing an increase in atmospheric $\mathrm{CO}_{2}$. This $\mathrm{CO}_{2}$ dissolves into oceanic surface waters, where it reacts with water to form bicarbonate $\left(\mathrm{HCO}_{3}^{-}\right)$and protons $\left(\mathrm{H}^{+}\right)$. Since the pre-industrial era, oceanic $\mathrm{CO}_{2}$ levels have risen by as much as $30 \%$ raising the $\mathrm{CO}_{2}$ partial pressure $\left(\mathrm{pCO}_{2}\right)$ to $400 \mu \mathrm{atm}$, which has caused the $\mathrm{pH}$ of ocean water to drop by 0.1 units ${ }^{1-4}$. Estimates suggest that if current trends continue, oceanic $\mathrm{pCO}_{2}$ could reach $1,000 \mu$ atm by the end of the century, reducing surface water $\mathrm{pH}$ by $0.3-0.4$ units $^{1,2,5}$.

Ocean acidification has been shown to have numerous behavioral and ecological effects on marine fishes ${ }^{6-13}$. It is thought that these effects are the consequence of elevated blood $\mathrm{HCO}_{3}{ }^{-}$that is the result of compensation to a respiratory acidosis ${ }^{14-16}$. It is generally accepted that marine fishes primarily compensate for a respiratory acidosis by transporting acid and base equivalents into the environment and plasma, respectively, through specialized gill ionocytes ${ }^{16-18}$. Apical transport of protons is thought to primarily occur through $\mathrm{Na}^{+} \mathrm{H}^{+}$exchangers NHE2 and NHE $3^{17-23}$. This pathway is particularly effective for marine fishes owing to the steep inward $\mathrm{Na}^{+}$gradient. Protons are produced from $\mathrm{CO}_{2}$ by cytoplasmic carbonic anhydrase (CA-c; ${ }^{24-26}$ ), which also produces $\mathrm{HCO}_{3}{ }^{-}$. This $\mathrm{HCO}_{3}{ }^{-}$is transported back into the plasma by the electrogenic $\mathrm{Na}^{+} \mathrm{HCO}_{3}{ }^{-}$co-transporter $(\mathrm{NBC})^{25,27}(1$ $\mathrm{Na}^{+}: 3 \mathrm{HCO}_{3}^{-} ;{ }^{-28,29}$ ), which has the benefit of raising plasma $\mathrm{HCO}_{3}^{-}$thereby offsetting the increase in plasma $\mathrm{CO}_{2}$ and returning $\mathrm{pH}$ to baseline values. More recently, studies in elasmobranchs have highlighted the importance of V-type ATPase (VHA) translocation in compensating for alkalosis ${ }^{30,31}$. It is as yet unclear if similar translocation to the apical membrane may play a role in compensating for an acidosis in teleost fishes.

The resilience of marine fish species to the long-term environmental degradation caused by ocean acidification is dependent on a number of factors. While evolutionary adaptation to ocean acidification is a possible route for some fishes with short generation times, typical evolutionary processes are thought to be too slow to provide a tangible route to resilience for long lived species ${ }^{32}$. Instead, a major factor is thought to be the presence of resilient genotypes that may already exist within a species or population ${ }^{32,33}$. A second major factor is the phenotypic plasticity of a species, either within an individual or through transgenerational mechanisms, as this is hypothesized to extend the time for more standard evolutionary processes to occur ${ }^{32-36}$. Due to clear implications of ocean 
A

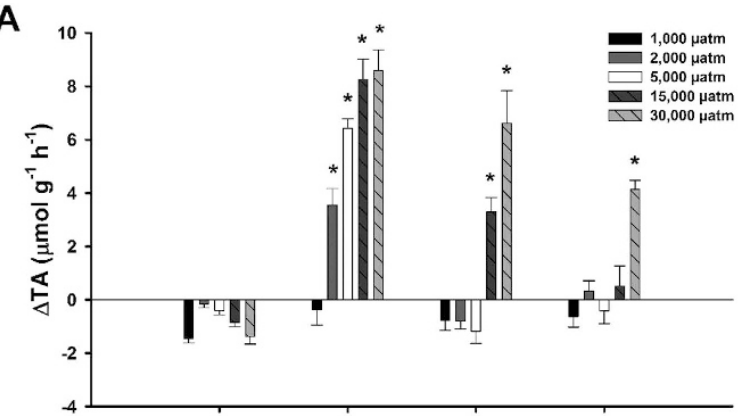

B

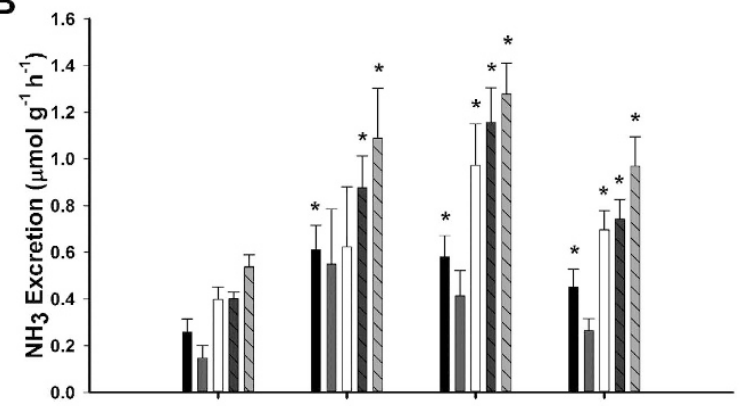

C

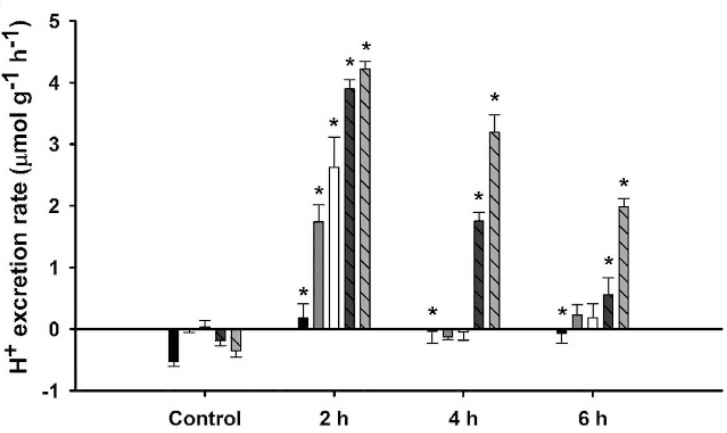

Figure 1. (A) Changes in titratable alkalinity, (B) Ammonia excretion, and (C) $\mathrm{Net}^{+}$excretion rates of red drum during control period and during $6 \mathrm{~h}$ post exposure to $1,000,2,000,5,000,15,000$ or $30,000 \mu \mathrm{atm}$ $\mathrm{CO}_{2}$. Significant differences from controls denoted by an asterisk (ANOVA, $\mathrm{P}<0.05$ ). All values are mean \pm S.E.M. $1,000 \mu$ atm $\mathrm{n}=6,2,000 \mu$ atm $\mathrm{n}=5,5,000 \mu$ atm $\mathrm{n}=12,15,000 \mu$ atm $\mathrm{n}=6,30,000 \mu$ atm $\mathrm{n}=6$.

acidification for fish acid-base balance, understanding the baseline capacity and plasticity of acid-base pathways is particularly relevant.

Estuarine fishes potentially act as ecologically and environmentally relevant models for the study of the impacts of ocean acidification and other low level acid-base disturbances. Estuaries play important roles in the life cycles of many marine teleost species by providing shelter and food to larval and juvenile individuals. Additionally, the biogeochemical aspects of estuaries - including regular eutrophication that drives increased levels of microbial respiration - makes them susceptible to changes driven by ocean acidification ${ }^{37-39}$. Conversely, the regular diel and seasonal shifts of $\mathrm{CO}_{2}$ in estuaries may provide fishes that inhabit these areas with a degree of built in resilience to acid-base disturbances. Red drum (Sciaenops ocellatus) utilize estuaries extensively during their early lifecycle ${ }^{40-42}$ and can potentially act as model species to determine the physiological mechanism employed by marine teleosts to compensate for hypercapnia driven acid-base disturbances. As such, this study aimed to characterize the physiological response of red drum to varying levels of respiratory acidosis. The first objective was to characterize the time course of whole animal acid excretion in response to increasing levels of hypercapnia. A second objective was to assess the short-term and long-term physiological plasticity in response to both environmentally relevant and physiologically extreme hypercapnia scenarios.

\section{Results}

Series I: Time course of acid excretion following hypercapnia exposure. During the 16h period, all doses - except the 5,000 $\mu$ atm dose - exhibited whole base excretion - as indicated by negative net $\mathrm{H}^{+}$excretion (Fig. 1C). The 5,000 $\mu$ atm dose exhibited slight net acid excretion but was not significantly different from zero (one sample t-test). All doses of $\mathrm{CO}_{2}$ significantly increased net $\mathrm{H}^{+}$excretion by $2 \mathrm{~h}$ post exposure. $\mathrm{Net}^{+}$ excretion in the 1,000 $\mu$ atm dose was significantly increased at all time points compared to the control period; however, excretion was not significantly different than zero at any time point (one sample t-test). The $2,000 \mu \mathrm{atm}$ 


\begin{tabular}{|l|c|c|c|}
\hline Treatment & Control & $\mathbf{3 0 , 0 0 0} \boldsymbol{\mu} \mathbf{a t m}$ & $\boldsymbol{\Delta}$ net $\mathbf{H}^{+}$flux \\
\hline $\begin{array}{l}\text { Single Exposure to } \\
\text { 30,000 } \mu \text { atm } \mathrm{CO}_{2}\end{array}$ & $-0.33 \pm 0.09$ & $3.97 \pm 0.12$ & $4.30 \pm 0.18$ \\
\hline $\begin{array}{l}\text { Repeat Exposure } \\
\text { to 30,000 } \mu \mathrm{atm} \\
\mathrm{CO}_{2}\end{array}$ & $-0.72 \pm 0.10$ & $3.77 \pm 0.24$ & $4.49 \pm 0.31$ \\
\hline
\end{tabular}

Table 1. Net $\mathrm{H}^{+}$excretion rates during control period and $2 \mathrm{~h}$ after initial and repeated exposures to $\mathbf{3 0 , 0 0 0} \mu$ atm $\mathrm{CO}_{2}$. All rates mean \pm S.E.M. $\mu \mathrm{mol} \mathrm{g} \mathrm{g}^{-1} \mathrm{~h}^{-1}$.

and $5,000 \mu \mathrm{atm} \mathrm{CO}_{2}$ doses returned to control excretion rates by $4 \mathrm{~h}$ post exposure. In both the $15,000 \mu \mathrm{atm}$ and $30,000 \mu$ atm $\mathrm{CO}_{2}$ doses, net $\mathrm{H}^{+}$excretion remained elevated throughout the time series, although in both cases excretion rates appeared to be returning to control levels. While the vast majority of net $\mathrm{H}^{+}$excretion was attributable to titratable acid flux (Fig. 1A), there was also widespread significant increases in $\mathrm{NH}_{3}$ excretion when exposed to elevated $\mathrm{CO}_{2}$ compared to control values (Fig. 1B). There was no significant effect of $1 \mathrm{mM}$ amiloride (mean \pm S.E.M. $=1.35 \pm 0.11$ ) on $\mathrm{H}^{+}$excretion versus DMSO controls (mean \pm S.E.M. $=1.38 \pm 0.08$; data not shown) during a $6 \mathrm{~h}$ flux period at $30,000 \mu \mathrm{atm} \mathrm{CO}_{2}$. Prior acclimation to $30,000 \mu \mathrm{atm} \mathrm{CO}_{2}$ had no effect on net $\mathrm{H}^{+}$excretion rate when re-exposed to $30,000 \mu \mathrm{atm} \mathrm{CO}_{2}$. As above, all individuals exhibited a net base excretion during the $16 \mathrm{~h}$ control period, which was followed by significant net $\mathrm{H}^{+}$excretion during initial $2 \mathrm{~h}$ exposure to $30,000 \mu \mathrm{atm} \mathrm{CO}_{2}$. There was no difference in net change of $\mathrm{H}^{+}$excretion rate during initial $2 \mathrm{~h}$ exposure to $30,000 \mu \mathrm{atm} \mathrm{CO}_{2}$ between individuals pre-exposed and novel exposed individuals (Table 1).

Series II: Branchial acclimation following hypercapnia exposure. Exposure to 1,000 $\mu$ atm nominal $\mathrm{CO}_{2}$ induced changes in only one gene during the initial $24 \mathrm{~h}$ exposure. $n b c$ was transiently upregulated at $4 \mathrm{~h}$ of exposure (Fig. 2). No changes were observed in expression of nhe1, nhe2, nhe3, ca-c, or vha during the $1,000 \mu \mathrm{atm} \mathrm{CO}_{2}$ exposure. Only nhe1 and vha exhibited significant changes in expression during the $6,000 \mu \mathrm{atm}$ $\mathrm{CO}_{2}$ exposure. At $24 \mathrm{~h}$ of $6,000 \mu \mathrm{atm} \mathrm{CO}_{2}$ exposure nhe 1 was significantly downregulated. At $1 \mathrm{~h}$ of $6,000 \mu \mathrm{atm}$ $\mathrm{CO}_{2}$ exposure $v$ ha was significantly downregulated, followed by a significant upregulation at $4 \mathrm{~h}$ of exposure that remained upregulated throughout the course of the exposure. No changes in expression were observed during the $6,000 \mu \mathrm{atm} \mathrm{CO}_{2}$ exposure in $n h e 2, n h e 3, c a-c$, or $n b c$ (Fig. 2). In contrast, the $30,000 \mu$ atm $\mathrm{CO}_{2}$ exposure induced significant upregulation of $n h e 2, n h e 3, n b c$, and $v h a$ as early as $4 \mathrm{~h}$ post-exposure, all of which remained elevated at $24 \mathrm{~h}$ exposure. nhe 1 expression was significantly elevated at $24 \mathrm{~h}$ post-exposure. No changes were observed in expression of $c a-c$ at 30,000 $\mu \mathrm{atm} \mathrm{CO}_{2}$ (Fig. 2). A final experiment assessed potential plasticity in response to more prolonged exposure to ocean acidification $\left(1,000 \mu \mathrm{atm} \mathrm{CO}_{2}\right)$; however, there was no significant effect at either $72 \mathrm{~h}$ or $14 \mathrm{~d}$ post-exposure (Fig. 3).

Immunofluorescence analysis of red drum gills verified that VHA was most abundantly expressed in ionocytes, as evidenced by co-localization with NKA, a known ionocyte marker (Fig. 4). Less abundant non-ionocyte expression was also apparent throughout the primary and secondary lamellae. While VHA and NKA were co-localized to the same cells, they did not exhibit sub-cellular co-localization under control conditions, as evidenced by the lack of overlapping fluorescence signal in 3 dimensional confocal reconstruction (Fig. 4B). These reconstructions suggest that VHA localization is mostly cytoplasmic, although some apical expression cannot be ruled out (Fig. 4B). No evidence of basolateral VHA localization was observed. To investigate the role of possible translocation to the apical membranes during compensation from an acidosis fish were exposed to $1,000 \mu \mathrm{atm}$, $6,000 \mu \mathrm{atm}$, and 30,000 $\mu \mathrm{atm}$ nominal $\mathrm{CO}_{2}$ for $1 \mathrm{~h}$, after which VHA localization was again assessed. A $1 \mathrm{~h}$ time point was chosen to coincide with peak acid excretion, based on the results from Series $I$. There was no evidence of translocation of VHA to the apical membrane at any hypercapnia exposure (data not shown).

\section{Discussion}

The results of this study largely support the conventional models with respect to marine acid-base balance in fish, and furthermore clearly demonstrate that red drum are quite effective at dealing with environmentally relevant acid-base disturbances $\left(\leq 6,000 \mu \mathrm{atm} \mathrm{CO}_{2}\right)$. While some degree of transcriptional change was observed in response to environmentally realistic disturbances, these responses were typically small and took place after acid excretion rates had returned to control levels. This would suggest that these responses play a relatively small role in compensation. These results are not entirely surprising as sub-adult red drum are estuarine-dependent, and therefore can routinely encounter diel shifts in environmental $\mathrm{CO}_{2}$ and $\mathrm{pH}$ levels. Nonetheless, more extreme disturbances resulted in wide-scale up-regulation of acid-base transporters demonstrating that acid-base regulation in red drum is responsive to environmental stress.

Our study of acid flux showed that the rate of $\mathrm{H}^{+}$excretion by red drum increased sequentially with increased $\mathrm{CO}_{2}$ partial pressure. Red drum responded quickly to the imposed systemic acidosis as the first $2 \mathrm{~h}$ of exposure exhibited the highest rates of $\mathrm{H}^{+}$excretion in all exposures. This supports previous work on a variety of marine species that have shown similar patterns ${ }^{19-21}$. After the $2 \mathrm{~h}$ time point, individuals exposed to the three lowest doses $\left(1,000,2,000\right.$, and 5,000 $\mu$ atm $\left.\mathrm{CO}_{2}\right)$ had all returned to zero or control levels suggesting that they had fully compensated for the acid-base disturbance. This data supports previous work on blood chemistry in red drum whereby fish were fully compensated by $24 \mathrm{~h}$ after 1,000 and $5,000 \mu \mathrm{atm} \mathrm{CO}_{2}{ }^{43,44}$. A similar study on the gulf toadfish (Opsanus beta) further supports these findings by showing that the blood $\mathrm{pH}$ decreases significantly in response to hypercapnia $\left(1,000\right.$ and $\left.1,900 \mu \mathrm{atm} \mathrm{CO}_{2}\right)$ as early as 15 minutes post exposure but returns to control levels within $2 \mathrm{~h}^{14}$. Interestingly, the excretion rates between the 15,000 and 30,000 $\mu$ atm doses at $2 \mathrm{~h}$ of exposure are similar. This could be interpreted as a maximum excretion rate of the system, which is approximately 

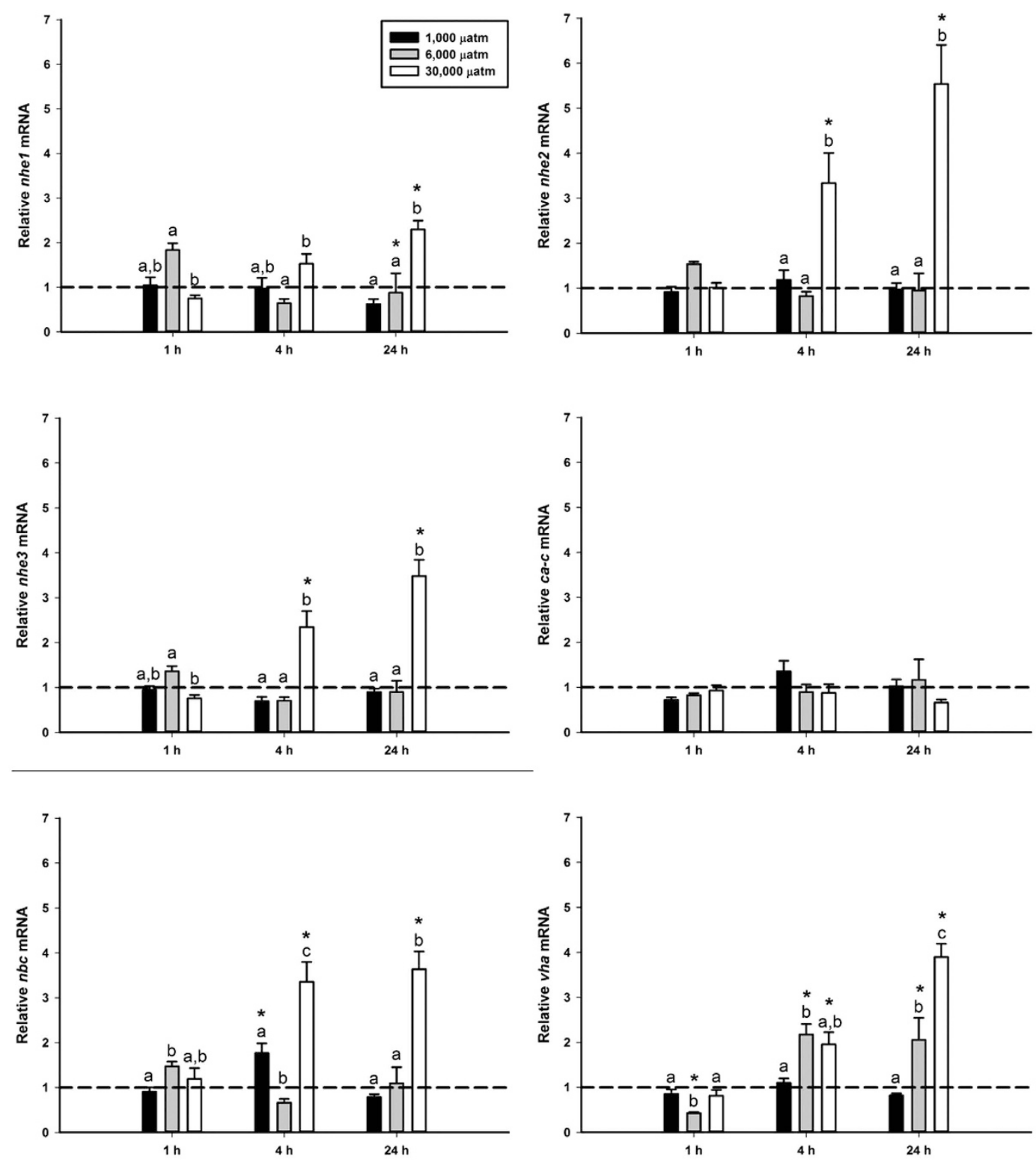

Figure 2. Gill expression of $\mathrm{H}^{+}$excretion pathways during initial $24 \mathrm{~h}$ exposure to $1,000,6,000$, and $30,000 \mu$ atm nominal $\mathrm{CO}_{2}$. Values set relative to control values denoted by the dashed lines at 1.0. Significant differences from controls within $\mathrm{CO}_{2}$ dose denoted by an asterisk. Letters denote significant differences within each timepoint. All values mean \pm S.E.M. $\mathrm{n}=7-8$.

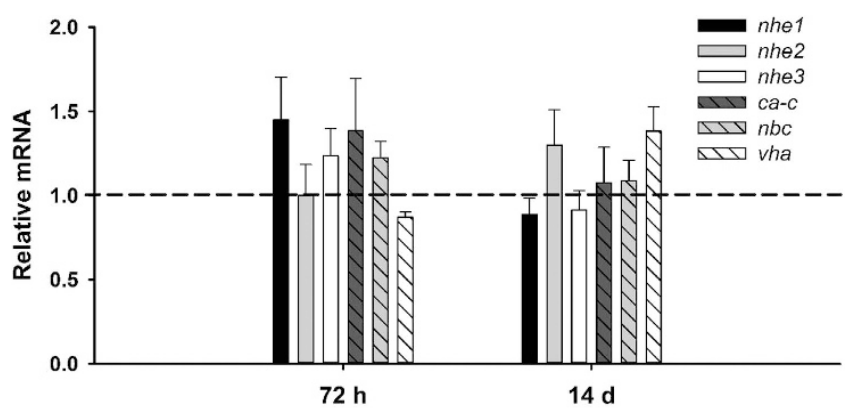

Figure 3. Gill expression of $\mathrm{H}^{+}$excretion pathways during prolonged exposure $(72 \mathrm{~h}$ and $14 \mathrm{~d})$ to environmentally relevant $1,000 \mu$ atm nominal $\mathrm{CO}_{2}$. Values set relative to control values (dashed line at 1.0). All values mean \pm S.E.M. $\mathrm{n}=7$. 

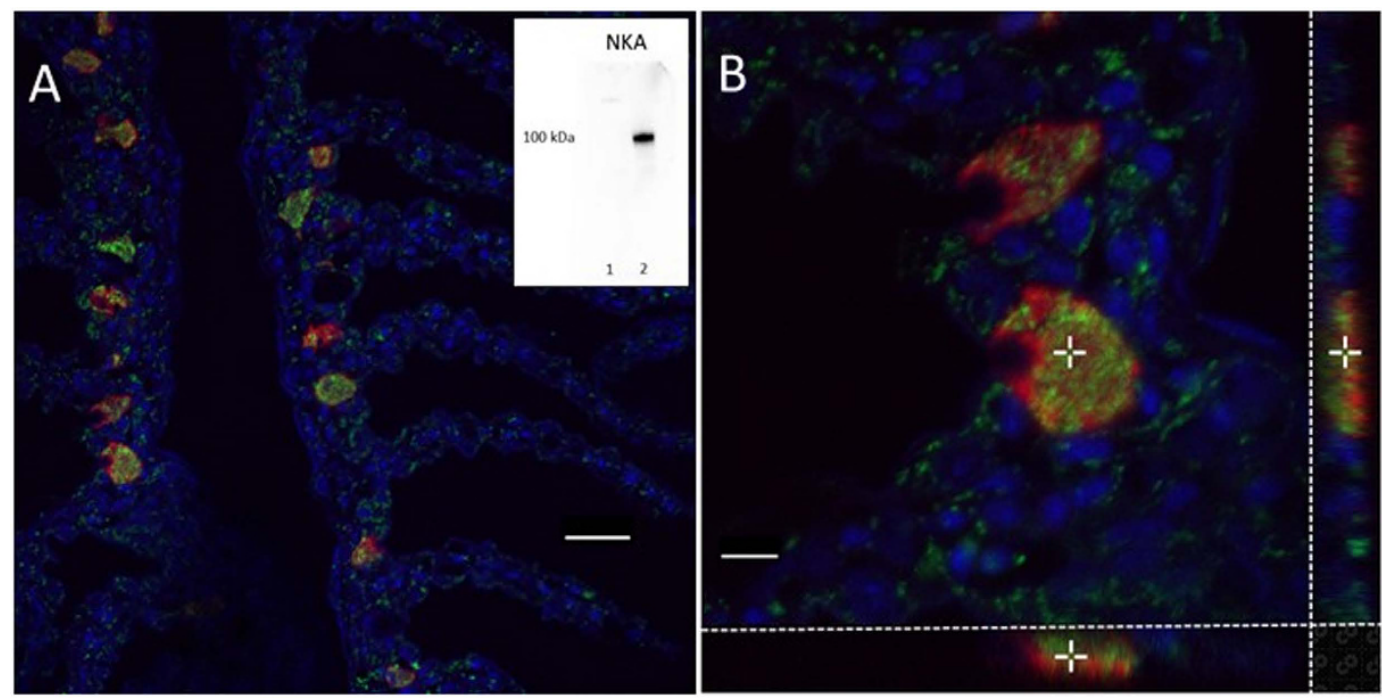

Figure 4. Immunofluorescent confocal micrographs showing branchial ionocytes. Red indicates $\mathrm{Na}^{+} \mathrm{K}^{+}$ ATPase (NKA) and green indicates V-type $\mathrm{H}^{+}$ATPase (VHA). Panel A: A representative image demonstrating the placement of ionocytes at the base of the secondary lamellae. Co-localization of NKA and VHA in ionocytes is demonstrated, but there is no evidence of sub-cellular co-localization (yellow). Additional VHA expression is found throughout the primary and secondary lamellae. Scale bar $=20 \mu \mathrm{m}$. Inset: Western blots demonstrating NKA antibody specificity in cytoplasmic (1) and membrane (2) protein fractions. Panel B: A 3-dimensional reconstruction of two ionocytes with showing $x-y$ (main panel), $x-z$ (lower panel, $50 \%$ scale) and $y-z$ (side panel, $50 \%$ scale) orientations. The cross point is provided for orientation. No yellow color is demonstrated in any view point. Scale bar $=5 \mu \mathrm{m}$. One hour of $1,000,6,000$ or $30,000 \mu \mathrm{atm} \mathrm{CO}_{2}$ exposure had no effect on VHA localization (data not shown).

$4 \mu \mathrm{mol} \mathrm{g} \mathrm{g}^{-1}$. Both the 15,000 and $30,000 \mu \mathrm{atm} \mathrm{CO}_{2}$ treatments remained elevated relative to the control period throughout the time trial; however, both exhibited a time-dependent trend of decreasing excretion rates towards control levels. Interestingly, the continued acid excretion suggests that the systemic acid-base disturbance was not fully compensated during the $2-4 \mathrm{~h}$ and $4-6 \mathrm{~h}$ intervals, yet the observed excretion rates were below maximum. This is likely related to a thermodynamic constraint on basolateral $\mathrm{HCO}_{3}{ }^{-}$re-uptake from ionocytes caused by the elevated plasma $\mathrm{HCO}_{3}{ }^{-}$. Nonetheless, these trends suggest that even at high levels of hypercapnia, red drum are able to efficiently compensate for an acidosis. Despite the trends in gene expression at $30,000 \mu$ atm $\mathrm{CO}_{2}$ that suggest plasticity under extreme hypercapnic stress, repeated exposure to $30,000 \mu$ atm $\mathrm{CO}_{2}$ did not have an effect on red drum's ability to excrete $\mathrm{H}^{+}$. Individuals that had been exposed to $30,000 \mu$ atm $\mathrm{CO}_{2}$ for $24 \mathrm{~h}$ exhibited the same apparent maximum excretion rate $\left(4 \mu \mathrm{mol} \mathrm{g}^{-1} \mathrm{~h}^{-1}\right)$ as those that had not been previously been exposed to elevated $\mathrm{CO}_{2}$. This suggests that the observed gene expression changes do not result in greater acid excretion capabilities; however, it is possible that they are required to maintain baseline function in the face of adverse intracellular conditions that may enhance protein turnover. Interestingly, $\mathrm{NH}_{3}$ excretion was significantly increased at the onset of elevated $\mathrm{CO}_{2}$ relative to control values. This is consistent with the ammonia trapping theory in which apical NHE function facilitates $\mathrm{NH}_{3}$ excretion ${ }^{45-47}$.

To more fully verify the predominant role of NHE proteins in net acid excretion, inhibition of acid excretion was attempted using the well-known NHE inhibitor, amiloride. However, inoculation with amiloride had no significant impact on net $\mathrm{H}^{+}$excretion rates of red drum exposed to $30,000 \mu \mathrm{atm} \mathrm{CO}_{2}$. This is in contrast to experiments run on freshwater teleosts where amiloride successfully inhibited the $\mathrm{H}^{+}$excretion pathways (primarily NHEs) in the gills ${ }^{48}$. While unlikely, it could be interpreted that these results suggest NHE is not a predominant route for apical $\mathrm{H}^{+}$transport. A much more plausible explanation is that seawater may reduce the effectiveness of amiloride, either through reduced solubility or competition with $\mathrm{Na}^{+49}$. While increasing the concentration of amiloride within the experimental chambers may have had more success in inhibiting $\mathrm{H}^{+}$excretion, amiloride becomes non-specific at higher concentrations - lessening the ability to accurately determine the source of excretion inhibition. These experiments highlight the difficulty in directly assessing the contributions of individual proteins to whole animal acid-base excretion.

The relatively few changes in gene expression found in the $1,000 \mu \mathrm{atm}$ and $6,000 \mu \mathrm{atm} \mathrm{CO}_{2}$ exposures provide further evidence that red drum have adequate machinery in place to compensate for environmentally relevant acid-base disturbances. Of the genes tested, none showed consistent responses at either the 1,000 $\mu$ atm or $6,000 \mu$ atm $\mathrm{CO}_{2}$ exposure. However, the transient upregulation of $n b c$ during the $1,000 \mu \mathrm{atm} \mathrm{CO}_{2}$ exposure, may indicate that $n b c$ is the limiting step in the compensation pathways. While it is possible that expression may have upregulated earlier than the earliest measured in this study, it is unlikely that the transcripts for these genes were increased and destroyed to return to control levels prior to the $1 \mathrm{~h}$ sampling point. A more plausible explanation is that red drum do not require upregulation of these genes until much later in the disturbance or until a higher level of disturbance has been reached. 


\begin{tabular}{|l|c|c|c|c|c|c|}
\hline Experiment & Treatment & $\begin{array}{c}\text { Temp } \\
\left({ }^{\circ} \mathbf{C}\right)\end{array}$ & $\begin{array}{c}\text { Salinity } \\
(\mathbf{p p t})\end{array}$ & $\mathbf{p H}$ & $\begin{array}{c}\text { Alkalinity } \\
(\boldsymbol{\mu} \mathbf{m o l})\end{array}$ & $\mathbf{p C O}_{2}(\boldsymbol{\mu a t m})$ \\
\hline Acid flux & $1,000 \mu \mathrm{atm}$ & $22 \pm 1$ & $30 \pm 1$ & $7.81 \pm 0.02$ & $2195 \pm 46$ & $1074 \pm 27$ \\
\hline & $2,000 \mu \mathrm{atm}$ & $23 \pm 1$ & $33 \pm 1$ & $7.59 \pm 0.03$ & $2134 \pm 22$ & $1756 \pm 131$ \\
\hline & $5,000 \mu \mathrm{atm}$ & $23 \pm 1$ & $34 \pm 1$ & $7.15 \pm 0.07$ & $2160 \pm 19$ & $5373 \pm 832$ \\
\hline & $15,000 \mu \mathrm{atm}$ & 23 & 32 & $6.69 \pm 0.01$ & $2318 \pm 9$ & $16281 \pm 549$ \\
\hline & $30,000 \mu \mathrm{atm}$ & 24 & 32 & $6.33 \pm 0.02$ & $2327 \pm 3$ & $38317 \pm 1466$ \\
\hline Pharmacology & Amiloride & 22 & 31 & $6.38 \pm 0.07$ & $2075 \pm 10$ & $31364 \pm 4822$ \\
\hline & DMSO & 22 & 31 & $6.34 \pm 0.06$ & $2082 \pm 13$ & $33589 \pm 4046$ \\
\hline Repeat exposure & $30,000 \mu \mathrm{atm}$ & $23 \pm 1$ & 32 & $6.37 \pm 0.01$ & $2211 \pm 3$ & $31459 \pm 156$ \\
\hline
\end{tabular}

Table 2. Water quality variables throughout acid flux experiments at varying levels of $\mathrm{CO}_{2}$. All values are mean \pm S.E.M.

An additional notable response was an observed down-regulation of $n h e 1$ at $24 \mathrm{~h}$ of exposure to $6,000 \mu \mathrm{atm}$ $\mathrm{CO}_{2}$. It is well-known that nhe1 is found on the basolateral membrane where it acts to move protect intracellular $\mathrm{pH}$ and contribute to plasma acidification by moving $\mathrm{H}^{+}$from the cell into the plasma ${ }^{17,50}$. nhe1 down-regulation is consistent with systemic acid-base balance in the face of an acidosis. It is somewhat surprising that neither nhe 2 nor nhe3 showed any up-regulation when exposed to 1,000 or $6,000 \mu \mathrm{atm} \mathrm{CO}_{2}$, as these two proteins are thought to be crucial in acid-base compensation ${ }^{17,18,21,23,51}$. This is likely the result of sufficient baseline activity to account for these acid-base disturbances, which is supported by the whole animal acid flux measurements discussed above. Interestingly, a previous study showed that red drum nhe 2 and nhe3 expression was also unchanged in the gill in response to freshwater transfer ${ }^{52}$. It is well-known that NHE proteins play a major role in $\mathrm{Na}^{+}$uptake in freshwater and many euryhaline species show significant up-regulation in response to freshwater transfer ${ }^{21,53-55}$. The fact that red drum do not show up-regulation to this osmoregulatory stress - presumably a stress that would require more consistent NHE function than in seawater - is further evidence that these animals may simply maintain high NHE protein levels in their gills under normal circumstances. Nonetheless, the proof of principle $30,000 \mu \mathrm{atm} \mathrm{CO}_{2}$ treatment indicated that nhe2 and nhe3 - as well as nhe1, nbc and vha - are transcriptionally responsive to an acidosis.

Another noteworthy finding from the $6,000 \mu \mathrm{atm}$ and $30,000 \mu \mathrm{atm} \mathrm{CO}_{2}$ treatments was the significant up-regulation of $v$ ha. While the involvement of VHA in freshwater acid-base compensation is well established ${ }^{56,57}$, this role is less certain for marine fishes. To date, most of the work examining VHA in marine acid-base compensation has focused on the translocation of cytoplasmic proteins to the basolateral membrane of ionocytes in response to an alkalosis ${ }^{30,31,58}$. However, it is important to note that this has not been demonstrated for a marine teleost. Our gene expression data suggest that VHA may play a role in $\mathrm{H}^{+}$excretion across the apical membrane in marine fishes. VHA is strongly co-localized with NKA in the red drum gills, as there were no observable non-VHA ionocytes. This is somewhat different from previous results with longhorn sculpin that showed that VHA was only expressed in a sub-population of ionocytes ${ }^{59}$. The localization of VHA within the cell does not provide much functional insight as the protein is found largely in the cytoplasmic fraction, although it appears to be oriented toward the apical pole. Unlike previous work on alkalosis, there was no evidence of translocation of VHA to the apical membrane during hypercapnia at $1,000 \mu \mathrm{atm}, 6,000 \mu \mathrm{atm}$, or $30,000 \mu \mathrm{atm} \mathrm{CO}_{2}$. While these results provide some support for the potential involvement of VHA in defending an acidosis, the lack of translocation or demonstrable apical localization suggest that VHA is not involved in apical $\mathrm{H}^{+}$extrusion. Further work should examine whether VHA translocation may occur under more prolonged exposure scenarios as a complement to the primary NHE pathways.

In conclusion the combination of whole animal acid flux, gene expression and immunohistochemistry presented here provides a thorough description of the mechanisms and plasticity of acid excretion pathways in red drum following elevated $\mathrm{CO}_{2}$. Evidence of plasticity was only observed at extreme $\mathrm{CO}_{2}$ levels, while environmentally relevant concentrations and those associated with climate change do not result in plasticity and can be completely compensated within $2 \mathrm{~h}$. This likely provides a physiological advantage in their estuarine habitat, where a number of factors can contribute to large shifts in ambient $\mathrm{CO}_{2}$ levels.

\section{Methods}

Animal Handling. Larval red drum were collected from Texas Parks and Wildlife hatchery in Corpus Christi, Texas. All fish were subsequently raised to the sub-adult stage at FAML. Fish were housed in recirculating systems with UV treated natural seawater collected from the Port Aransas ship channel with intermittent partial renewal. All tanks were aerated and ammonia was controlled by circulating water through a biofilter. Temperature was controlled using automated in-line heater/chiller units. $\mathrm{CO}_{2}$ was kept low through regular partial water replacement using ancillary flow-through lines. All fish were held on a 14h:10 h light dark cycle. Fish were fed daily with commercially available Aquamax pelleted dry food and fish were acclimated to control conditions in the facility for two weeks prior to experimentation. All experiments were conducted in accordance with protocols approved by the University of Texas at Austin Institutional Animal Care and Use Committee.

Whole Animal Acid Flux Measurements. Food was withheld from sub-adult red drum $(\mathrm{n}=36$, mean \pm S.E.M $=15.0 \pm 0.6 \mathrm{~g}$ ) for $24 \mathrm{~h}$ prior to and throughout the experiment to avoid digestive/metabolic influences on acid-base regulation. Fish were placed in individual chambers (approximately $365 \mathrm{~mL}$ ) with 


\begin{tabular}{|l|c|c|c|c|c|}
\hline Dose & Temp $\left({ }^{\circ} \mathbf{C}\right)$ & Salinity $(\mathbf{p p t})$ & $\mathbf{p H}$ & Alkalinity $(\boldsymbol{\mu M})$ & $\mathbf{p C O}_{2}(\mu \mathrm{atm})$ \\
\hline Control & 23 & 32 & $8.15 \pm 0.01$ & $2,394 \pm 17$ & $477 \pm 13$ \\
\hline $1,000 \mu \mathrm{atm}$ & 23 & 32 & $7.80 \pm 0.01$ & $2,348 \pm 2$ & $1,154 \pm 35$ \\
\hline $6,000 \mu \mathrm{atm}$ & 23 & 32 & $7.13 \pm 0.01$ & $2,488 \pm 13$ & $6,181 \pm 77$ \\
\hline $30,000 \mu \mathrm{atm}$ & 23 & 32 & $6.44 \pm 0.01$ & $2,346 \pm 1$ & $29,159 \pm 364$ \\
\hline
\end{tabular}

Table 3. Water quality variables for phenotypic plasticity studies. All values are mean \pm S.E.M.

\begin{tabular}{|c|c|c|c|}
\hline Gene & Accession \# & Orientation & Sequence \\
\hline \multirow{2}{*}{ ef1-a } & \multirow{2}{*}{ KJ958539 } & $\mathrm{F}$ & GTTGCTGGATGTCCTGCACG \\
\hline & & $\mathrm{R}$ & GTCCGTGACATGAGGCAGACTG \\
\hline \multirow{2}{*}{ nhe1 } & \multirow{2}{*}{$\underline{\text { KU899107 }}$} & F & AATGAGCTGCTGCACATCCTCG \\
\hline & & $\mathrm{R}$ & CAGACCACTCCGAGGACAGC \\
\hline \multirow{2}{*}{ nhe2 } & \multirow{2}{*}{$\underline{\text { KJ958540 }}$} & $\mathrm{F}$ & CGGTTAAGCCTGATGGCCCTC \\
\hline & & $\mathrm{R}$ & TTGCAAACGAAGCCAGCAGC \\
\hline \multirow{2}{*}{ nhe3 } & \multirow{2}{*}{$\underline{\text { KJ958541 }}$} & $\mathrm{F}$ & CAAGGTGCAGACCTTCACGCTG \\
\hline & & $\mathrm{R}$ & ACGAGGATGGCTCCCATGTT \\
\hline \multirow{2}{*}{$\mathrm{ca}-\mathrm{c}$} & \multirow{2}{*}{$\underline{\text { KM387716.1 }}$} & $\mathrm{F}$ & TGACATTCGCAGACGACTCCGA \\
\hline & & $\mathrm{R}$ & AGCAGGATACTTGGTCCCTTCCA \\
\hline \multirow{2}{*}{$\mathrm{nbc}$} & \multirow{2}{*}{$\underline{\text { KM387714.1 }}$} & $\mathrm{F}$ & TCTTCATCTACGACGCTTTCAA \\
\hline & & $\mathrm{R}$ & TCATATTGAGTGACGAGGTTGG \\
\hline \multirow{2}{*}{ vha } & \multirow{2}{*}{$\underline{\text { KU899108 }}$} & $\mathrm{F}$ & CCTACCATTGAGCGTATCATCA \\
\hline & & $\mathrm{R}$ & CGTAGGAGCTCATGTCAGTCAG \\
\hline
\end{tabular}

Table 4. List of primers used for real-time PCR. All sequences are $5^{\prime}$ to $3^{\prime}$ and reverse primers are reverse compliments of the genetic sequence.

flow-through control seawater (salinity $32 \mathrm{ppt}$, temperature $22^{\circ} \mathrm{C}, \mathrm{pH} 8.12$ ) and aeration. All individuals were given an $8 \mathrm{~h}$ chamber acclimation period prior to experimentation. After the acclimation period, the water source was removed and individuals underwent a $16 \mathrm{~h}$ control acid flux to establish normocapnia baselines. This was followed by a $1 \mathrm{~h}$ flush period prior to initiating hypercapnia. Preliminary experiments revealed that all significant acid flux occurred during the first $6 \mathrm{~h}$ (data not shown), and therefore hypercapnia exposures were limited to $6 \mathrm{~h}$ with acid flux measurements taken every $2 \mathrm{~h}$. Hypercapnia exposures were initiated by removing the water source and switching aeration from ambient room air to room air mixed with nominal 1,000, 2,000,5,000, 15,000, or $30,000 \mu \mathrm{atm}\left(0.76,1.52,3.8,11.4,22.8 \mathrm{mmHg}\right.$, respectively) $\mathrm{CO}_{2}$ (Table 2 ). A repeated exposure series at $30,000 \mu$ atm $\mathrm{CO}_{2}$ was also performed to assess whether increased gene expression conferred increased acid excretion rates. This series first exposed individuals to $\mathrm{CO}_{2}$ for $24 \mathrm{~h}$ followed by a $24 \mathrm{~h}$ recovery period under control conditions to return blood chemistry to control conditions. Immediately following the $24 \mathrm{~h}$ recovery period, acid flux experiments were performed as above with the exception that the flux period consisted of a single $2 \mathrm{~h}$ interval at $30,000 \mu \mathrm{atm} \mathrm{CO}_{2}$.

For all flux periods, water samples were taken at the beginning and end of the flux period for determination of titratable alkalinity and ammonia. The exact time of each sampling point was noted and $\mathrm{pH}$ was measured - calibrated with NBS buffers - at the onset of each flux period to verify $\mathrm{CO}_{2}$ treatment levels. Temperature, $\mathrm{pH}$, titratable alkalinity and salinity measurements were also taken from the flush reservoir to validate $\mathrm{CO}_{2}$ partial pressures. At the conclusion of control and hypercapnia flux periods the individual chambers with water were weighed and the weight of the fish and empty chamber was subtracted to obtain the flux chamber volume. Immediately following water sample collection, each $25 \mathrm{~mL}$ flux period water sample was aerated with pure $\mathrm{N}_{2}$ gas for 15 minutes to remove any contribution of respiratory $\mathrm{CO}_{2}$ from the sample. Samples collected to verify $\mathrm{CO}_{2}$ treatment levels did not undergo $\mathrm{N}_{2}$ aeration. $10 \mathrm{~mL}$ of each sample was then titrated at $22^{\circ} \mathrm{C}$ with $0.1 \mathrm{~N} \mathrm{HCl} \mathrm{using} \mathrm{an} \mathrm{auto-}$ mated Apollo SciTech AS-ALK2 alkalinity titrator and accompanying software to determine titratable alkalinity. Ammonia concentrations were measured in each sample using a standard colorimetric assay ${ }^{60}$.

To elucidate the role of NHE's in acid excretion, amiloride - a known NHE inhibitor - was introduced at the onset of $\mathrm{CO}_{2}$ exposure. Amiloride inhibition experiments were performed as above with the exception that experimental chambers were inoculated with $1 \mathrm{mM}$ amiloride or $0.1 \%$ DMSO vehicle at the onset of hypercapnia exposure. Initial water samples were taken $15 \mathrm{~min}$ after drug inoculation and flux periods consisted of a single $6 \mathrm{~h}$ interval at $30,000 \mu \mathrm{atm} \mathrm{CO}_{2}$.

Gene expression exposures. Sub adult red drum were held in $300 \mathrm{~L}$ recirculating tanks supplied with filtered, UV treated Port Aransas ship channel water $(\mathrm{pH}=8.15)$ for at least two weeks prior to $\mathrm{CO}_{2}$ exposure. Fish were then transferred into a $300 \mathrm{~L}$ exposure tank or a $300 \mathrm{~L}$ control tank. Food was withheld for at least $24 \mathrm{~h}$ prior to sampling. Initial experiments were performed at control, 1,000, 6,000, and 30,000 $\mu$ atm nominal $\mathrm{CO}_{2}$ for $4 \mathrm{~h}$ and $24 \mathrm{~h}(\mathrm{n}=8 /$ treatment, mean body weight \pm S.E. $\mathrm{M}=39.5 \pm 5.8 \mathrm{~g})$. A second series performed $1 \mathrm{~h}$ exposures at 
all $\mathrm{CO}_{2}$ levels $(\mathrm{n}=8$ /treatment, mean \pm S.E.M $=29.6 \pm 1.1 \mathrm{~g})$. Each level of hypercapnia was maintained by aerating tanks through a gas-water equilibration tower with $\mathrm{CO}_{2}$ input controlled by gas mass flow controllers; control tanks were aerated with ambient room air. $\mathrm{pCO}_{2}$ exposure levels were calculated using $\mathrm{CO}_{2}$ Calc software ${ }^{61}$ using $\mathrm{pH}$ and titratable alkalinity measurements (Table 3). Immediately following exposure, specimens were euthanized with an overdose of tricane methanesulfonate (MS 222; $250 \mathrm{mg} / \mathrm{l}$ buffered with $500 \mathrm{mg} / \mathrm{l} \mathrm{NaHCO}_{3}$ ) followed by spinal transection. Gill lamellae were excised and placed RNALater, and subsequently stored at $-80^{\circ} \mathrm{C}$ until processing. Gill arches were also collected from control and $1 \mathrm{~h}$ exposed fish and fixed in $\mathrm{z}$-fix (Anatech Ltd.) overnight then stored in $70 \%$ ethanol until processing.

Molecular Methods. Real time PCR primers were developed for $n b c$ and $v h a$ ( $\beta$-subunit), whereas primers for nhe1, nhe2, nhe3, $c a-c$, and elongation factor $1 \alpha(e f 1 \alpha)$ had previously been developed for red drum ${ }^{52}$. Full length sequences for both $n b c$ and $v h a$ were identified from an in-house gill/intestine transcriptome using Blaststation software. The identified sequences were then verified against the NCBI database using a standard Blast search. Primer pairs were identified using Primer3Plus software package ${ }^{62}$. All primers and GenBank accession numbers for related sequences can be found in Table 4 .

Gill lamellae stored in RNALater were washed twice in $500 \mu \mathrm{L}$ PBS before homogenization. Total RNA isolation was performed using TriReagent according to manufacturer protocols, and quantified using an ND-1000 spectrophotometer (Thermo Scientific). Total RNA was treated for potential DNA contamination by incubating with DNase 1 (Thermo Scientific), according to manufacturer protocols. cDNA synthesis was performed on $1 \mu$ g of total RNA using RevertAid M-Mulv reverse transcriptase (Thermo Scientific), according to manufacturer protocols. For all cDNA synthesis runs no reverse transcriptase controls were performed to test for genomic DNA contamination. Samples were diluted 10 -fold using nuclease free water and stored at $-20^{\circ} \mathrm{C}$ until qPCR analysis.

qPCR analysis was performed using the Maxima SYBR Green kit (Thermo Scientific). Reactions were prepared according to the manufacturer's protocols with the exception that a $12.5 \mu$ l total reaction volume was used. All reactions were processed using an MX3000 P qPCR machine (Stratagene) with accompanying software. A serial dilution was used for standard curves to determine the reaction efficiency of each primer pair. PCR efficiencies ranged from 74.2 to $100.8 \%$ with an $\mathrm{R}^{2} \geq 0.97$. For all genes, negative and no reverse-transcriptase control reactions were performed. The $\mathrm{CT}$ values for each sample were used to assess relative abundance of each gene in relation to the control gene efl $\alpha$ using the delta-delta CT method ${ }^{63}$. Note that $e f 1 \alpha$ is a well-validated control gene for use in teleost fish ${ }^{64}$ that has been previously used in red drum ${ }^{43,52,65}$.

Immunofluorescence Methods. Prior to staining, samples were dehydrated by three washes with $95 \%$ ethanol for 60 minutes followed by three washes with $100 \%$ ethanol for 45 minutes followed by a $1 \mathrm{~h}$ butanol wash and an overnight soak in butanol. Samples were then washed twice for 90 minutes in Histochoice clearing agent. Two paraplast washes were then conducted at $58^{\circ} \mathrm{C}$ for $1 \mathrm{~h}$ before samples were set in paraffin and allowed to harden at room temperature. Samples were then stored at $4^{\circ} \mathrm{C}$ until sectioning. Samples were sectioned at $20 \mu$ $\mathrm{m}$ and mounted onto Superfrost Plus slides where they were rehydrated, deparaffinised and soaked in DI water until ready to stain. Note that thick sections were used to allow for $3 \mathrm{D}$ confocal imaging of entire ionocytes. Each slide contained two sections so that no-primary antibody controls could be run concurrently with each sample. Antigen recovery was performed by heating slides in boiling $10 \mathrm{mM}$ citrate buffer solution three times for 5 minutes. Hydrophobic barriers were drawn around each sample and samples were washed in blocking buffer (PBST with 5\% fetal calf serum) twice for 5 minutes. Samples were then incubated with primary antibodies for NKA [1:100] and VHA [1:200] at $4{ }^{\circ} \mathrm{C}$ overnight. The primary polyclonal rabbit antibody for NKA (sc-28800) was obtained from the Santa Cruz Biotechnology and its effectiveness in red drum was verified by a Western blot that yielded only one band of approximately $100 \mathrm{kDa}$. The primary monoclonal mouse antibody for VHA was obtained from Santa Cruz Biotechnology and its effectiveness in red drum had previously been validated by our lab ${ }^{65}$. While there are commercial antibodies for NBC, NHE2 and NHE3, the target epitopes show low sequence similarity to red drum. Following primary incubation samples were washed in blocking buffer three times for 5 minutes then incubated with secondary antibodies - goat anti-rabbit Alexa Flour 555 [1:500] and goat anti-mouse Alexa Flour 488 [1:500] (Life Technologies) - in the dark for $1 \mathrm{~h}$. Samples were then washed with blocking buffer three times for 5 minutes, stained with Sudan Black for 20 minutes to eliminate autofluorescence, and washed in PBS for 10 minutes. Finally, samples were washed with blocking buffer three times for 5 minutes and mounted using Vectashield with DAPI and stored in the dark at $4{ }^{\circ} \mathrm{C}$ until imaged. Imaging was completed using a Nikon C2+ confocal microscope system with a Nikon Eclipse Ti-E inverted microscope and utilizing NIS-Element imaging software for image acquisition, processing, and analysis.

Statistical Methods. Gene expression data during the first $24 \mathrm{~h}$ of exposure to all treatments was assessed using a two-way ANOVA and Holm-Sidak post-hoc test using pairwise multiple comparisons. Prolonged exposures to $1,000 \mu$ atm $\mathrm{CO}_{2}$ had concurrently run control groups for $72 \mathrm{~h}$ and $14 \mathrm{~d}$ and thus were assessed by Student's $t$-test against the respective control. All statistical tests were performed with a fiducial level of significance of $\mathrm{p}<0.05$. Acid-flux experiments were analyzed using one way repeated measures ANOVA with Holm-Sidak post-hoc test using multiple comparisons. Changes in $\mathrm{H}^{+}$excretion during the amiloride exposure - against controls and between treatments - were analyzed using a two-way ANOVA with Holm-Sidak post-hoc multiple comparisons against controls.

Ethical Approval. This article does not contain any studies with human participants performed by any of the authors. All applicable international, national, and/or institutional guidelines for the care and use of animals were followed. All procedures performed in studies involving animals were in accordance with the ethical standards of the University of Texas at Austin Institutional Animal Care and Use Committee (AUP-2015-00147). 


\section{References}

1. Raven, J. et al. Ocean acidification due to increasing atmospheric carbon dioxide. Coral Reefs 5, 1-59 (2005).

2. Orr, J. C. et al. Anthropogenic ocean acidification over the twenty-first century and its impact on calcifying organisms. Nature 437, 681-686 (2005).

3. Caldeira, K. \& Wickett, M. E. Oceanography: anthropogenic carbon and ocean pH. Nature 425, 365 (2003).

4. Meehl, G. et al. In Climate Change 2007: The Physical Science Basis 747-846, at http://www.ipcc.ch/ipccreports/ar4-wg1.htm (Cambridge University Press, 2007).

5. Caldeira, K. Ocean model predictions of chemistry changes from carbon dioxide emissions to the atmosphere and ocean. J. Geophys. Res. 110, 1-12 (2005).

6. Ishimatsu, A., Hayashi, M. \& Kikkawa, T. Fishes in high-CO2, acidified oceans. Mar. Ecol. Prog. Ser. 373, 295-302 (2008).

7. Munday, P. L. et al. Replenishment of fish populations is threatened by ocean acidification. Proc. Natl. Acad. Sci. USA 107, 12930-12934 (2010).

8. Munday, P. L. et al. Ocean acidification impairs olfactory discrimination and homing ability of a marine fish. Proc. Natl. Acad. Sci. USA 106, 1848-1852 (2009).

9. Simpson, S. D. et al. Ocean acidification erodes crucial auditory behaviour in a marine fish. Biol. Lett. 7, 917-920 (2011).

10. Dixson, D. L., Munday, P. L. \& Jones, G. P. Ocean acidification disrupts the innate ability of fish to detect predator olfactory cues. Ecol. Lett. 13, 68-75 (2010).

11. Cripps, I. L., Munday, P. L. \& McCormick, M. I. Ocean acidification affects prey detection by a predatory reef fish. PLoS One 6, 1-7 (2011).

12. Nilsson, G. E. et al. Near-future carbon dioxide levels alter fish behaviour by interfering with neurotransmitter function. Nat. Clim. Chang. 2, 201-204 (2012).

13. Ferrari, M. C. O. et al. Effects of ocean acidification on learning in coral reef fishes. PLoS One 7, 1-10 (2012).

14. Esbaugh, A. J., Heuer, R. \& Grosell, M. Impacts of ocean acidification on respiratory gas exchange and acid-base balance in a marine teleost, Opsanus beta. J. Comp. Physiol. B Biochem. Syst. Environ. Physiol. 182, 921-934 (2012).

15. Strobel, A. et al. Metabolic shifts in the Antarctic fish Notothenia rossii in response to rising temperature and PCO2. Front. Zool. 9, $1-15$ (2012).

16. Heuer, R. M. \& Grosell, M. Physiological impacts of elevated carbon dioxide and ocean acidification on fish. AJP Regul. Integr. Comp. Physiol. 307, R1061-R1084 (2014).

17. Claiborne, J. B. et al. A mechanism for branchial acid excretion in marine fish: identification of multiple $\mathrm{Na}+/ \mathrm{H}+$ antiporter $(\mathrm{NHE})$ isoforms in gills of two seawater teleosts. J. Exp. Biol. 202, 315-324 (1999).

18. Claiborne, J. B., Edwards, S. L. \& Morrison-Shetlar, A. I. Acid-base regulation in fishes: Cellular and molecular mechanisms. J. Exp. Zool. 293, 302-319 (2002).

19. Claiborne, J. B. et al. Molecular detection and immunological localization of gill $\mathrm{Na}+/ \mathrm{H}+$ exchanger in the dogfish (Squalus acanthias). Am. J. Physiol. Regul. Integr. Comp. Physiol. 294, R1092-R1102 (2008).

20. Edwards, S. L., Claiborne, J. B., Morrison-Shetlar, A. I. \& Toop, T. Expression of $\mathrm{Na}+/ \mathrm{H}+$ exchanger mRNA in the gills of the Atlantic hagfish (Myxine glutinosa) in response to metabolic acidosis. Comp. Biochem. Physiol. - A Mol. Integr. Physiol. 130, 81-91 (2001).

21. Edwards, S. L. et al. The effect of environmental hypercapnia and salinity on the expression of NHE-like isoforms in the gills of a euryhaline fish (Fundulus heteroclitus). J. Exp. Zool. Part A Comp. Exp. Biol. 303, 464-475 (2005).

22. Guffey, S. C., Fliegel, L. \& Goss, G. G. Cloning and characterization of Na+/H+ Exchanger isoforms NHE2 and NHE3 from the gill of Pacific dogfish Squalus suckleyi. Comp. Biochem. Physiol. Part B Biochem. Mol. Biol. 188, 46-53 (2015).

23. Michael, K. et al. Adjustments of molecular key components of branchial ion and pH regulation in Atlantic cod (Gadus morhua) in response to ocean acidification and warming. Comp. Biochem. Physiol. Part - B Biochem. Mol. Biol. 193, 33-46 (2016).

24. Esbaugh, A. J. et al. Cytoplasmic carbonic anhydrase isozymes in rainbow trout Oncorhynchus mykiss: comparative physiology and molecular evolution. J. Exp. Biol. 208, 1951-1961 (2005).

25. Perry, S. F. \& Gilmour, K. M. Acid-base balance and CO2 excretion in fish: Unanswered questions and emerging models. Respir. Physiol. Neurobiol. 154, 199-215 (2006).

26. Gilmour, K. M. \& Perry, S. F. Carbonic anhydrase and acid-base regulation in fish. J. Exp. Biol. 212, 1647-1661 (2009).

27. Perry, S. F. \& Laurent, P. In Fish Ecophysiology (eds Rankin, J. C. \& Jensen, F. B.) 231-264 (1993).

28. Taylor, J. R., Mager, E. M. \& Grosell, M. Basolateral NBCe1 plays a rate-limiting role in transepithelial intestinal HCO3- secretion, contributing to marine fish osmoregulation. J. Exp. Biol. 213, 459-468 (2010).

29. Kurita, Y. et al. Identification of intestinal bicarbonate transporters involved in formation of carbonate precipitates to stimulate water absorption in marine teleost fish. Am. J. Physiol. Regul. Integr. Comp. Physiol. 294, R1402-12 (2008).

30. Roa, J. N., Munévar, C. L. \& Tresguerres, M. Feeding induces translocation of vacuolar proton ATPase and pendrin to the membrane of leopard shark (Triakis semifasciata) mitochondrion-rich gill cells. Comp. Biochem. Physiol. -Part A Mol. Integr. Physiol. 174, 29-37 (2014).

31. Tresguerres, M., Parks, S. K., Wood, C. M. \& Goss, G. G. V-H+-ATPase translocation during blood alkalosis in dogfish gills: interaction with carbonic anhydrase and involvement in the postfeeding alkaline tide. Am. J. Physiol. Regul. Integr. Comp. Physiol. 292, R2012-R2019 (2007).

32. Pfister, C. A. et al. Detecting the Unexpected: A Research Framework for Ocean Acidification. Environ. Sci. Technol. 48, $9982-9994$ (2014).

33. Gonzalez, A., Ronce, O., Ferriere, R. \& Hochberg, M. E. Evolutionary rescue: an emerging focus at the intersection between ecology and evolution. Philos. Trans. R. Soc. Lond. B. Biol. Sci. 368, 1-8 (2013).

34. Pespeni, M. H. et al. Evolutionary change during experimental ocean acidification. Proc. Natl. Acad. Sci. 110, 6937-6942 (2013).

35. Miller, G. M., Watson, S.-A., Donelson, J. M., McCormick, M. I. \& Munday, P. L. Parental environment mediates impacts of increased carbon dioxide on a coral reef fish. Nat. Clim. Chang. 2, 858-861 (2012).

36. Salinas, S. \& Munch, S. B. Thermal legacies: Transgenerational effects of temperature on growth in a vertebrate. Ecol. Lett. 15, 159-163 (2012).

37. Feely, R. A. et al. The combined effects of ocean acidification, mixing, and respiration on $\mathrm{pH}$ and carbonate saturation in an urbanized estuary. Estuar. Coast. Shelf Sci. 88, 442-449 (2010).

38. Cai, W.-J. et al. Acidification of subsurface coastal waters enhanced by eutrophication. Nat. Geosci. 4, 766-770 (2011).

39. Lonthair, J., Ern, R. \& Esbaugh, A. J. The early life stages of an estuarine fish, the red drum (Sciaenops ocellatus), are tolerant to high $\mathrm{pCO}_{2}$. ICES J. Mar. Sci. J. du Cons. fsw225, doi: 10.1093/icesjms/fsw225 (2017).

40. Matlock, G. C. The Life History of Red Drum. Red Drum Aquaculture 1-21 (1987).

41. Rooker, J. \& Holt, S. Utilization of subtropical seagrass meadows by newly settled red drum Sciaenops ocellatus:patterns of distribution and growth. Mar. Ecol. Prog. Ser. 158, 139-149 (1997).

42. Stunz, G. W., Minello, T. J. \& Levin, P. S. Growth of newly settled red drum Sciaenops ocellatus in different estuarine habitat types. Mar. Ecol. Prog. Ser. 238, 227-236 (2002).

43. Esbaugh, A. J., Ern, R., Nordi, W. M. \& Johnson, A. S. Respiratory plasticity is insufficient to alleviate blood acid-base disturbances after acclimation to ocean acidification in the estuarine red drum, Sciaenops ocellatus. J. Comp. Physiol. B Biochem. Syst. Environ. Physiol. 186, 97-109 (2015). 
44. Ern, R. \& Esbaugh, A. J. Hyperventilation and blood acid-base balance in hypercapnia exposed red drum (Sciaenops ocellatus). J. Comp. Physiol. B Biochem. Syst. Environ. Physiol. 186, 447-460 (2016).

45. Cooper, C. A., Wilson, J. M. \& Wright, P. A. Marine, freshwater and aerially acclimated mangrove rivulus (Kryptolebias marmoratus) use different strategies for cutaneous ammonia excretion. Am. J. Physiol. - Regul. Integr. Comp. Physiol. 304, R599-R612 (2013).

46. Nawata, C. M., Hirose, S., Nakada, T., Wood, C. M. \& Kato, A. Rh glycoprotein expression is modulated in pufferfish (Takifugu rubripes) during high environmental ammonia exposure. J. Exp. Biol. 213, 3150-3160 (2010).

47. Wood, C. M. \& Nawata, C. M. A nose-to-nose comparison of the physiological and molecular responses of rainbow trout to high environmental ammonia in seawater versus freshwater. J. Exp. Biol. 214, 3557-3569 (2011).

48. Kumai, Y. \& Perry, S. F. Ammonia excretion via Rhcgl facilitates Na+ uptake in larval zebrafish, Danio rerio, in acidic water. AJP Regul. Integr. Comp. Physiol. 301, R1517-R1528 (2011).

49. Benos, D. J. Amiloride: a molecular probe of sodium transport in tissues and cells. Am. J. Physiol. 242, C131-C145 (1982).

50. Orlowski, J. \& Grinstein, S. Diversity of the mammalian sodium/proton exchanger SLC9 gene family. Pflugers Arch. Eur. J. Physiol. 447, 549-565 (2004).

51. Ivanis, G., Esbaugh, A. J. \& Perry, S. F. Branchial expression and localization of SLC9A2 and SLC9A3 sodium/hydrogen exchangers and their possible role in acid-base regulation in freshwater rainbow trout (Oncorhynchus mykiss). J. Exp. Biol. 211, 2467-2477 (2008).

52. Watson, C. J., Nordi, W. M. \& Esbaugh, A. J. Osmoregulation and branchial plasticity after acute freshwater transfer in red drum, Sciaenops ocellatus. Comp. Biochem. Physiol. Part A Mol. Integr. Physiol. 178, 82-89 (2014).

53. Gilmour, K. M. et al. Compensatory regulation of acid-base balance during salinity transfer in rainbow trout (Oncorhynchus mykiss). J. Comp. Physiol. B Biochem. Syst. Environ. Physiol. 182, 259-274 (2012).

54. Scott, G. R., Claiborne, J. B., Edwards, S. L., Schulte, P. M. \& Wood, C. M. Gene expression after freshwater transfer in gills and opercular epithelia of killifish: insight into divergent mechanisms of ion transport. J. Exp. Biol. 208, 2719-2729 (2005).

55. Reilly, B. D., Cramp, R. L., Wilson, J. M., Campbell, H. A. \& Franklin, C. E. Branchial osmoregulation in the euryhaline bull shark, Carcharhinus leucas: a molecular analysis of ion transporters. J. Exp. Biol. 214, 2883-2895 (2011).

56. Goss, G. G., Perry, S. F., Fryer, J. N. \& Laurent, P. Gill morphology and acid-base regulation in freshwater fishes. Comp. Biochem. Physiol. - A Mol. Integr. Physiol. 119, 107-115 (1998).

57. Lin, H., Pfeiffer, D., Vogl, A., Pan, J. \& Randall, D. Immunolocalization of H+-ATPase in the gill epithelia of rainbow trout. J. Exp. Biol. 195, 169-83 (1994).

58. Tresguerres, M., Parks, S. K. \& Goss, G. G. Recovery from blood alkalosis in the Pacific hagfish (Eptatretus stoutii): Involvement of gill V-H+-ATPase and Na+/K+-ATPase. Comp. Biochem. Physiol. - A Mol. Integr. Physiol. 148, 133-141 (2007).

59. Catches, J. S., Burns, J. M., Edwards, S. L. \& Claiborne, J. B. Na+/H+ antiporter, V-H+-ATPase and Na+/K+-ATPase immunolocalization in a marine teleost (Myoxocephalus octodecemspinosus). J. Exp. Biol. 209, 3440-3447 (2006).

60. Verdouw, H., van Echted, C. J. A. \& Dekkers, E. M. J. Ammonia determination based on indophenol formation with sodium salicylate. Water Res 12, 399-402 (1978).

61. Robbins, L. L., Hansen, M. E., Kleypas, J. A. \& Meylan, S. C. CO2calc - a user-friendly seawater carbon calculator for Windows, Mac OS X and iOS (iPhone). U.S. Geol. Surv. Open-File Rep. 2010-1280 17 (2010).

62. Untergasser, A. et al. Primer3Plus, an enhanced web interface to Primer3. Nucleic Acids Res. 35, W71-W74 (2007).

63. Pfaffl, M. Quantification strategies in real-time PCR Michael W. Pfaffl. A-Z Quant. PCR 87-112, doi: http://dx.doi.org/10.1007/ s10551-011-0963-1 (2004).

64. Tang, R., Dodd, A., Lai, D., McNabb, W. C. \& Love, D. R. Validation of zebrafish (Danio rerio) reference genes for quantitative realtime RT-PCR normalization. Acta Biochim. Biophys. Sin. (Shanghai). 39, 384-390 (2007).

65. Esbaugh, A. J. \& Cutler, B. Intestinal $\mathrm{Na}^{+}, \mathrm{K}^{+}, 2 \mathrm{Cl}^{-}$cotransporter 2 plays a crucial role in hyperosmotic transitions of a euryhaline teleost. Physiol. Rep. 4, e13028 (2016).

\section{Acknowledgements}

Funding for this project was provided by a National Science Foundation research grant (EF 1315290) to AJE. We would like to thank the Texas Parks and Wildlife Hatchery for providing experimental animals and Jeff Kaiser for animal husbandry assistance. This study was funded the National Science Foundation (EF 1315290).

\section{Author Contributions}

E.B.A. performed all experiments, analysis and writing. A.J.E. provided general supervision, critical editing and microscopic analysis.

\section{Additional Information}

Competing Interests: The authors declare no competing financial interests.

How to cite this article: Allmon, E. B. and Esbaugh, A. J. Carbon dioxide induced plasticity of branchial acidbase pathways in an estuarine teleost. Sci. Rep. 7, 45680; doi: 10.1038/srep45680 (2017).

Publisher's note: Springer Nature remains neutral with regard to jurisdictional claims in published maps and institutional affiliations.

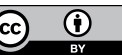

This work is licensed under a Creative Commons Attribution 4.0 International License. The images or other third party material in this article are included in the article's Creative Commons license, unless indicated otherwise in the credit line; if the material is not included under the Creative Commons license, users will need to obtain permission from the license holder to reproduce the material. To view a copy of this license, visit http://creativecommons.org/licenses/by/4.0/

(c) The Author(s) 2017 